\title{
Norepinephrine Induces BDNF and Activates CREB and Discriminates among Protein Kinase C Isoforms in Cultured Embryonic Hippocampal Neurons
}

\author{
Michael Chen*, Amelia Russo-Neustadt \\ Department of Biological Sciences, California State University, Los Angeles, CA, USA \\ Email: *mchen@calstatela.edu
}

How to cite this paper: Chen, M. and Russo-Neustadt, A. (2017) Norepinephrine Induces BDNF and Activates CREB and Discriminates among Protein Kinase C Isoforms in Cultured Embryonic Hippocampal Neurons. Neuroscience \& Medicine, 8, 53-67.

https://doi.org/10.4236/nm.2017.84008

Received: September 8, 2017

Accepted: December 1, 2017

Published: December 4, 2017

Copyright $\odot 2017$ by authors and Scientific Research Publishing Inc. This work is licensed under the Creative Commons Attribution International License (CC BY 4.0). http://creativecommons.org/licenses/by/4.0/

\begin{abstract}
Medications acting as mood stabilizers work by enhancing and maintaining the concentration of circulating synaptic neurotransmitters, which then activate a plethora of various intracellular signal transduction and second messenger cascades. Previously, we showed that two of these cascades, the PI-3K and MAPK pathways, are activated by cross-talk with the protein kinase A cAMP cascade and by brain-derived neurotrophic factor (BDNF), an immediate-early gene whose expression is the result of phosphorylation of the transcription factor, cAMP response element binding protein (CREB). In the current study, we extend these findings to include the protein kinase $C$ (PKC) pathway. Western blotting studies show that application of norepinephrine to cultured hippocampal neurons leads to increased expression of BDNF, phosphorylation of CREB, activation of growth-associated protein-43 (GAP-43) and activation of $\mathrm{PKC} \mu$ and $\mathrm{PKC} \theta_{t 538}$. Because GAP-43 is a putative substrate for PKC, the results of this study lend further support of a G-protein coupled receptor cross-talking to an entirely distinct intracellular pathway that is known to be involved in neuritogenesis.
\end{abstract}

\section{Keywords}

BDNF, CREB, PKD, PKC, Hippocampus

\section{Introduction}

Norepinephrine is a key neurotransmitter, whose actions are putatively known to play a critical role in several types of mood disorders, such as major depres- 
sion [1] [2] [3] [4] in which, it is presumed that anything that can boost the amount of circulating synaptic norepinephrine (and serotonin), such as physical exercise and antidepressant medications, will ameliorate depressive symptoms [5] [6] [7].

We had previously shown that application of norepinephrine to cultured hippocampal neurons results in increased expression of brain-derived neurotrophic factor (BDNF), phosphorylation of cAMP response element binding protein (CREB) and activation of the PI-3K and MAPK cascades, which are known to promote neuronal survival [8]. However, besides these two pro-survival cascades, other pathways also contribute to neuronal protection and survival by activating proteins, such as BDNF and CREB, which play key roles in plasticity.

The protein kinase $\mathrm{C}(\mathrm{PKC})$ family of structurally related phospholipid-dependent serine-threonine kinases comprises nearly a dozen different isoforms, most of which are involved in neural differentiation [9] and postnatal neural development [10], although their developmental profile differs among them [11] [12] [13]. Among this rather vast array of different isozymes, a related enzyme, protein kinase $\mathrm{D}(\mathrm{PKD})$ or $\mathrm{PKC} \mu$, displays multiple unique features that qualify it as a distant relative of the other PKC isozymes in both its regulation and substrate selectivity [14].

Moreover, there is now much compelling evidence that several PKCs, more specifically PKD, play a critical role in hippocampal neuronal plasticity [15] [16] by maintaining the structural integrity of the Golgi and trafficking proteins involved in dendritic arborization [17] and axonal elongation [18] and stabilizing cytoskeletal proteins in dendritic spines [19] in response to environmental or intracellular stimuli, such as learning [20] [21] [22] [23], memory [24] [25] and adaptations to pathological threats, such as developing mood disorders [26]. Consistently, PKD phosphorylation increased upon glutamate receptor stimulation [27], which is putatively activated during long-term potentiation [28]. One key protein that has received much attention because of its role in such plasticity is GAP-43 [29], whose expression in the adult hippocampus is coincident with dendritic outgrowth [30] and is a substrate for PKC [31]. There is, however, no evidence for whether GAP-43 is also a substrate for PKD.

Because both BDNF [32] [33] [34] and GAP-43 [35] are potent mediators of plasticity, there is much evidence that these two proteins are both up- or downregulated, although not necessarily at the same time and place in the hippocampus [36] [37]. Rather, the extent of their co-expression depends on the type of conditions that may cause the hippocampus to adapt to new challenges, such as with physical exercise [38], learning [33], aging [39] and withstanding toxic [40], pathological [41] [42] or traumatic [43] insult. On the other hand, neither stress [44] nor antidepressant-induced reversal of stress [45] changed hippocampal BDNF and GAP-43 levels, compared to those of untreated controls.

However, neuronal or animal age is also an important factor in determining the levels of BDNF and GAP-43 upon stimulation. Seizures induced into the brains of young animals resulted in an increase in BDNF, although GAP-43 le- 
vels did not change, relative to that of controls [46]. More recently, low-frequency stimulation to cultured hippocampal neurons resulted in increased expression of a wide battery of synaptic proteins involved in structural changes that accompany synaptic plasticity, among them of which were BDNF and GAP-43 [47]. And application of norepinephrine to hippocampal astrocytes resulted in increased BDNF release into the culture medium [48].

Thus, given the relatively sparse literature on $\mathrm{PKD}$, it is hypothesized that norepinephrine induces BDNF expression via $\mathrm{PKD}$ activation. We therefore extend our earlier findings done with the PI-3K and MAPK cascades [8] to PKD-mediated BDNF expression and CREB activation via the application of norepinephrine to cultured hippocampal neurons.

\section{Materials and Methods}

\subsection{Drugs and Chemicals}

Norepinephrine and bisindoylmaleimide were purchased from Sigma Chemical Co. (St. Louis, MO). Dulbecco's modified eagle medium (DMEM) was purchased from ATCC (Manassas, VA). Bisindoylmaleimide (GF109203X (GF)) was dissolved in DMSO; at no time did the concentration of DMSO exceed 0.5\% of the total volume of each tissue culture well.

\subsection{Antibodies}

Anti-BDNF was purchased from Santa Cruz Biotech (Santa Cruz, CA). Antiphospho-PKC $\mu$ (PKD), anti-phospho-PKC $\mu_{5916}$, anti-phospho-PKC $\mu_{\mathrm{S} 744 / 748}$, antiphospho-PKC $\alpha / \beta$, anti-phospho-PKC $\delta_{5643}$, anti-phospho-PKC $\delta_{\mathrm{T} 505}$, anti-phospho-PKC $\theta_{\text {T538, }}$, anti-phospho-PKC $\zeta \lambda$, anti-pan PKC, anti-phospho-GAP-43, anti-GAP-43, anti-phospho-CREB and anti-CREB were purchased from Cell Signaling Technology (Danvers, MA). Anti-GAPDH was purchased from Advanced Immunochemical Inc. (Long Beach, CA). Anti-rabbit IgG and antimouse IgG, were purchased from Amersham-Pharmacia Biotech (Piscataway, NJ).

\subsection{Animals: Ethics Statement}

All efforts were made to minimize the number of rats used. We have abided by the use of the ethical treatment of laboratory animals as specified in the National research Council's Guide for the Care and the Use of Laboratory Animals (1996). The Institutional Animal Care and Use Committee (IACUC) and the Institutional Review Board-Human Subjects at California State University, Los Angeles, approved this project. The IACUC Protocol number is AW 10-1.

\subsection{Hippocampal Dissection at Embryonic Day 18 (E18)}

Dissection of embryonic hippocampi at E18 has been described in great detail elsewhere [8] [49]. Briefly, four pregnant female Sprague-Dawley rats (120 - 150 g, two months of age, Charles River, Wilmington, MA) were sacrificed by deca- 
pitation on their $18^{\text {th }}$ day of gestation. The embryos (14 per mother rat) were then quickly placed on ice and their hippocampi excised into Ca-Mg-free medium [50] and rinsed therein. Then, $0.125 \%$ trypsin was added, and the hippocampi placed in a $37^{\circ} \mathrm{C}$-water bath and gently shaken every several minutes for $10 \mathrm{~min}$, followed by adding $10 \%$ fetal bovine serum/DMEM to quench the reaction. All medium was then drained and replaced with $5 \mathrm{ml}$ DMEM in which the hippocampi were triturated through a siliconized glass Pasteur pipet to liberate individual cells. Neurons were then counted on a glass hemacytometer and then plated in tissue culture plates that were pre-coated with poly- - -lysine at a density of 50,000 cells $/ \mathrm{cm}^{2}$. Neurons were then allowed to acclimate to their new environment for three days in an incubator at $37^{\circ}, 5 \% \mathrm{CO}_{2}$.

\subsection{Application of Norepinephrine and Bisindoylmaleimide (GF) to Hippocampal Neurons}

On the day of drug treatment, GF (5 $\mu \mathrm{M}[51])$ and/or norepinphrine (100 nM [8]) was added first to randomly selected wells in the tissue culture plates in the following order: GF + norepinephrine, norepinephrine alone, GF alone, vehicle (controls, DMSO). Returned plates to the incubator for $2 \mathrm{hr}$, at the end of which, cells were lysed and harvested in lysis buffer. Cells were then boiled for $5 \mathrm{~min}$ and then triturated through a $26-G$ needle/syringe to sheer genomic DNA. The volumes were measured, equal volumes of Laemmli buffer [52] added, and then the cells were stored at $-70^{\circ} \mathrm{C}$ till SDS-PAGE/Western blotting. Protein concentrations were determined using the method of Lowry [53].

\subsection{SDS-PAGE/Western Blotting}

SDS-PAGE/Western blotting has been described in great detail elsewhere [49]. Briefly, equal volumes of cell lysates were added to $10 \%$ polyacrylamide gels, electrophoresed at $100 \mathrm{~V}$ for $2 \mathrm{hr}$, electrotransferred to nitrocellulose membranes (Biorad, Hercules, CA) at $100 \mathrm{~V}$ for $2 \mathrm{hr}$, and then Western blotting performed according to the manufacturer's specific instructions for each respective antibody. Following probing with the secondary antibody, to visualize protein immunoreactivity, nitrocellulose membranes were incubated in enhanced chemiluminescence reagents (Amersham Pharmacia-Biotech, Piscataway, NJ) and apposed to hyperfilm (Amersham Pharmacia-Biotech, Piscataway, NJ). Membrane blots first exposed to anti-BDNF were then stripped (100 mM 2-mercaptoethanol, $2 \%$ SDS, $62.5 \mathrm{mM}$ tris- $\mathrm{HCl}, \mathrm{pH} 6.7,55^{\circ} \mathrm{C}$, for $10 \mathrm{~min}$ ) and then reprobed with anti-GAPDH; all membrane blots first probed with the phosphoform of an antibody were then stripped and then re-probed with the total (pan) form of the respective antibody.

Optical densities of lightly exposed bands were then quantified using computer-assisted densitometry (MCID, St. Catherine's, Ontario, Canada). Optical densities of BDNF and the phospho-forms were then arithmetically divided by those 
of GAPDH and the pan forms, respectively. The linear portion of a standard curve was used to calibrate the range of a gray scale where all optical densities were taken.

\subsection{Statistical Analyses}

Western blot data of BDNF, phospho-CREB and phospho-GAP-43 were based on four treatment groups: controls, norepinephrine-treated, GF-treated, and norepinephrine---GF-treated. Omnibus $\mathrm{F}$ values were calculated using a oneway ANOVA, followed by Fisher's post-hoc LSD to evaluate statistically significant differences of pair-wise comparisons.

\section{Results}

\subsection{PKC $\delta_{\mathrm{s} 643}$ and PKC $\mu$ (PKD) Are the only PKCs That Responded to Bisindoylmaleimide}

Western blotting screening of the eight phospho-PKC isozymes resulted in, for the most part, no significant differences among the four treatments in E18 hippocampal neurons. In most cases, GF did not suppress the activity of any of the phospho-PKC isoforms, relative to that of controls; the only exception was that of phospho-PKC $\delta_{\mathrm{S} 643}\left(\mathrm{~F}_{(3,8)}=4.70, \mathrm{p}=0.0355\right.$; Figure 1$)$, whose activity was significantly less than that of controls as a result of GF. Likewise, application of

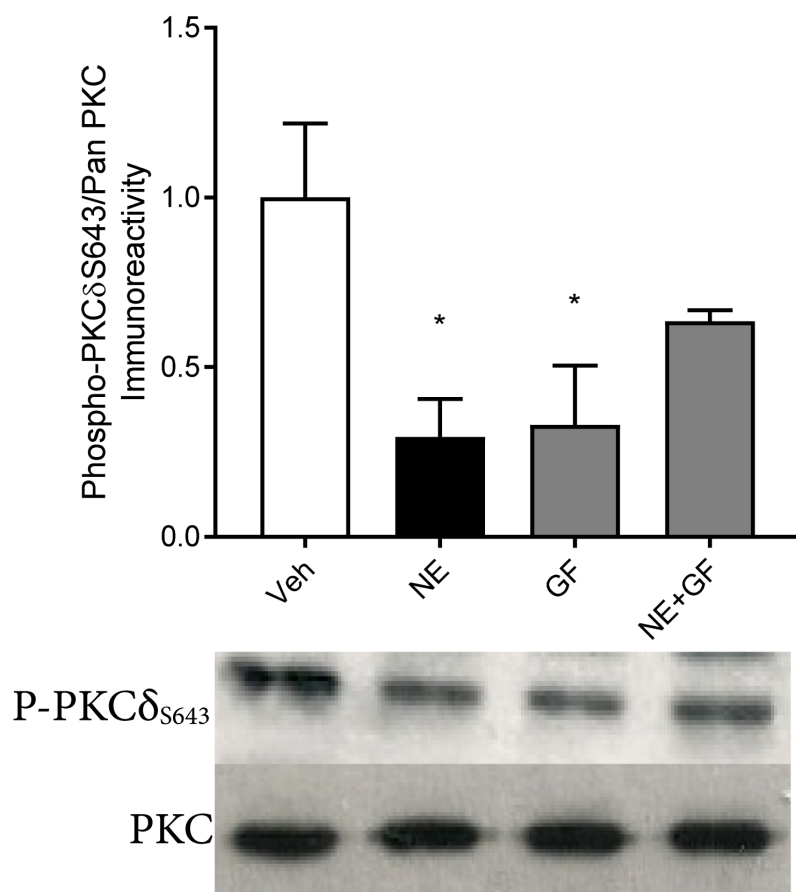

Figure 1. Both norepinephrine and GF decrease phospho-PKCS643 activity. Both norepinephrine $(\mathrm{p}=0.011)$ and GF $(\mathrm{p}=0.014)$ significantly decreased $\mathrm{P}-\mathrm{PKC} \delta_{\mathrm{S} 643}$ activity, relative to that of vehicle controls. The combination of the two (NE + GF) increased phosphorylation of $\mathrm{PKC} \delta_{\mathrm{S} 643}$ to a level where it was statistically comparable to that of controls. Veh, vehicle control; NE, norepinephrine (100 nM); GF, bisindoylmaleimide (5 $\mu \mathrm{M}) ;{ }^{\star}$ Significantly different from vehicle controls. 
norepinephrine did not result in increased activity with most $\mathrm{PKC}$ isoforms and in some cases (e.g., phospho-PKC $\delta_{\mathrm{S} 643}$ (Figure 1)), actually resulted in less activity, compared to those of controls. Only phospho- $\mathrm{PKC} \mu\left((\mathrm{PKD}) \mathrm{F}_{(3,8)}=4.354, \mathrm{p}\right.$ $=0.0427$; Figure 2(a))) and phospho- $\mathrm{PKC}_{\mathrm{T} 538}\left(\mathrm{~F}_{(3,8)}=4.647, \mathrm{p}=0.0366\right.$, Figure 2(b)) increased in response to norepinephrine, compared to those of controls. Application of norepinephrine, whether GF was present or not, resulted in a significant increase in phospho-PKD activity, compared to those of vehicle-treated controls (Figure 2(a)).

\subsection{Norepinephrine Activates GAP-43}

Application of norepinephrine to E18 hippocampal neurons resulted in a significant increase in phospho-GAP-43, compared to that of vehicle-treated controls, whereas GF significantly decreased phospho-GAP-43 levels $\left(\mathrm{F}_{(3,32)}=91.02, \mathrm{p}<\right.$ 0.001; Figure 3).

\subsection{Norepinephrine Induces BDNF}

Application of norepinephrine to E18 hippocampal neurons resulted in a significant increase in BDNF, compared to those of vehicle-treated controls, whereas GF significantly decreased BDNF levels, relative to those receiving norepinephrine $\left(\mathrm{F}_{(3,32)}=38.22, \mathrm{p}<0.001\right.$; Figure 4). However, although GF decreased
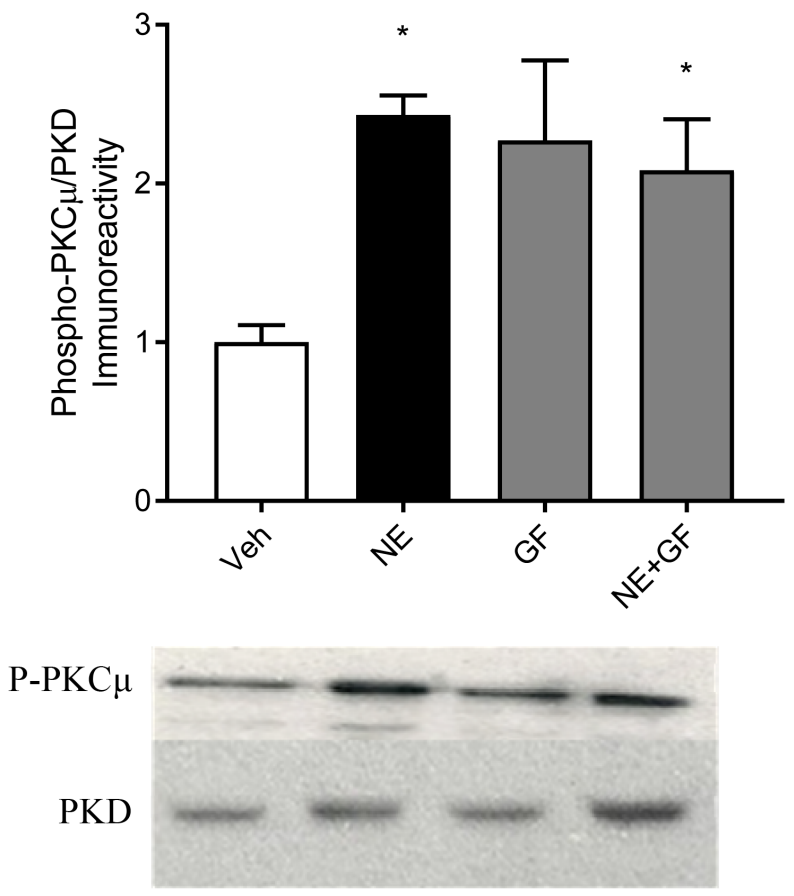

(a)

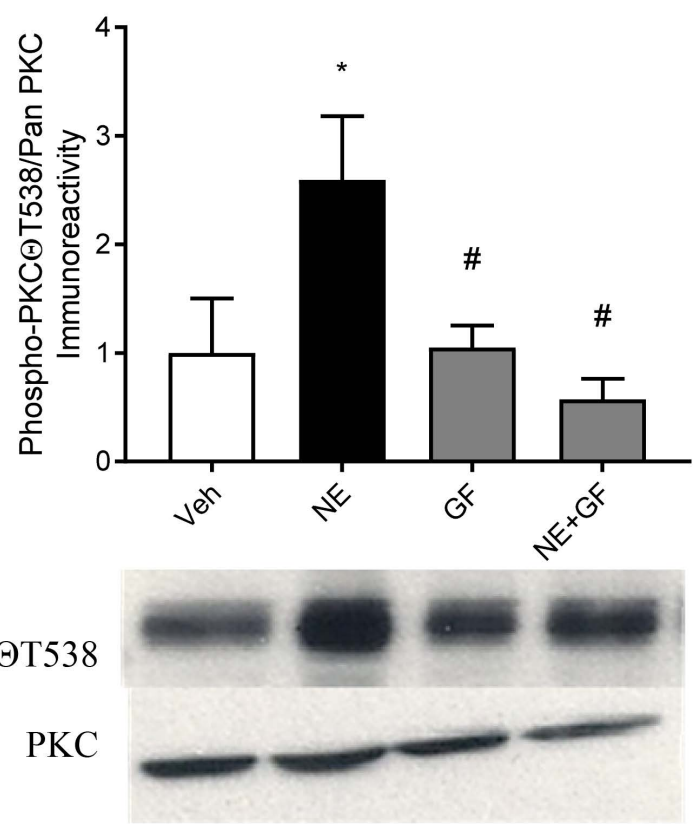

(b)

Figure 2. Norepinephrine activates PKC isoforms. (a) Norepinephrine alone ( $\mathrm{p}=0.0114)$, GF alone ( $\mathrm{p}=0.020)$ and the two combined ( $p=0.0388$ ) significantly increased phosphorylation of PKD above that of controls; (b) Norepinephrine alone activates $\mathrm{PKC} \theta_{\mathrm{T} 538}$ relative to that of vehicle controls $(\mathrm{p}=0.0253)$. Norpinephrine activation of $\mathrm{PKC} \theta_{\mathrm{T} 538}$ is also significantly higher than that of NE + GF ( $p=0.0084)$ and GF alone $(\mathrm{p}=0.0288)$. Veh, vehicle control; NE, norepinephrine $(100 \mathrm{nM})$; GF, bisindoylmaleimide $(5 \mu \mathrm{M})$; ${ }^{\star S}$ Significantly different from vehicle controls; \#Significantly different from NE. 


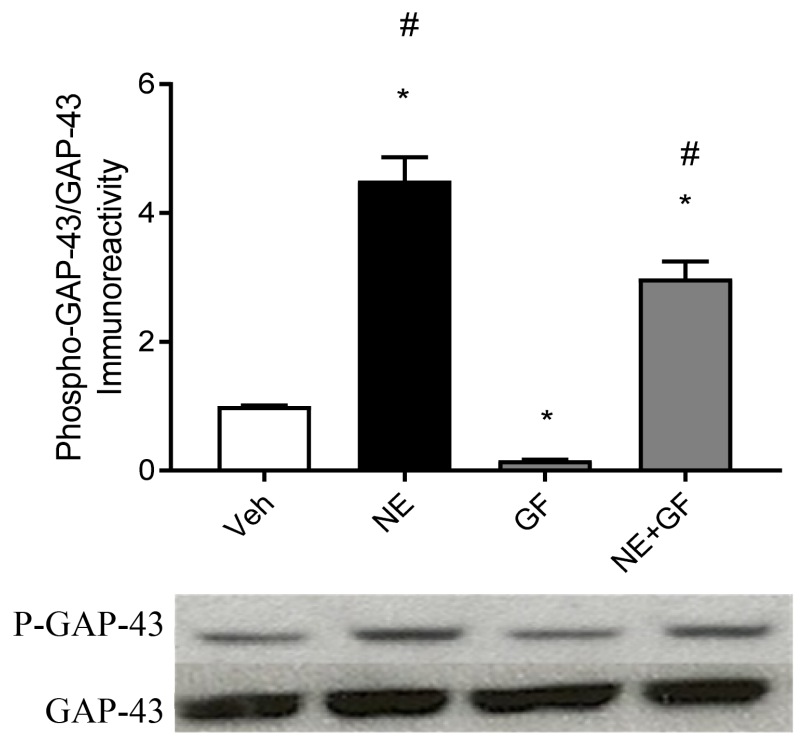

Figure 3. Norepineprhine increases, while GF decreases GAP-43 phosphorylation. Norepinephrine significantly increased phosphorylation of GAP-43 above that of vehicle controls $(\mathrm{p}<0.001)$ and when combined with GF $(\mathrm{NE}+\mathrm{GF})$, was decreased, but still significantly higher than that of vehicle controls $(\mathrm{p}<0.001)$. GF, on the other hand, resulted in significantly lower GAP-43 phosphorylation levels, compared to that of controls ( $\mathrm{p}<$ 0.001). Veh, vehicle control; NE, norepinephrine (100 nM); GF, bisindoylmaleimide (5 $\mu \mathrm{M})$; ${ }^{\star}$ Significantly different from vehicle controls; \#Significantly different from GF at $\mathrm{p}<$ 0.001 .

BDNF levels, compared to that of norepinephrine, BDNF levels still remained significantly higher than those of controls $(\mathrm{p}<0.001$, Figure 4$)$.

\subsection{Norepinephrine Activates CREB}

Application of norepinephrine to E18 hippocampal neurons resulted in a significant increase in phosphorylated CREB, compared to that of vehicle-treated controls, whereas GF significantly decreased phospho-CREB levels, relative to that of controls $\left(\mathrm{F}_{(3,32)}=136.76, \mathrm{p}<0.001\right.$; Figure 5).

\section{Discussion}

Our previous studies conducted in cultured hippocampal neurons showed that application of norepinephrine resulted in increased BDNF expression, CREB phosphorylation and activation of two key cell survival-promoting cascades [8], which were also up-regulated in response to nutrient deprivation stress from the cultured medium [54] [55]. In the current study, we explored the effects of norepinephrine on $\mathrm{PKD}$, a key regulator in plasticity [15] [16], and its effects on BDNF, CREB and GAP-43, which PKC is known to phosphorylate [31]. As before, we found that norepinephrine up-regulated BDNF and activated CREB [8]. However, this could also indicate that PKA [56], MAPK [57] [58] or PI-3K/Akt [7] [54] [57] [59] [60] are also phosphorylating CREB through pathway cross-talk [8] [55] [58]. And although this narrows down the list of possibilities and 

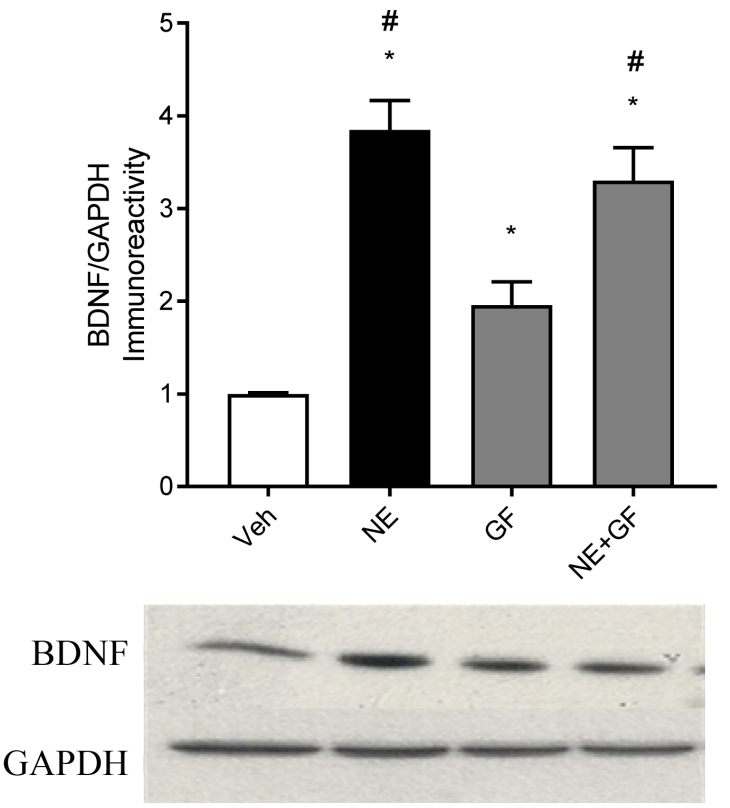

Figure 4. Norepinephrine increases BDNF expression. Norepinephrine significantly increased expression of BDNF above that of vehicle controls $(\mathrm{p}<0.001)$, but when combined with GF (NE + GF), was decreased only very slightly and was statistically higher than that of vehicle controls $(\mathrm{p}<0.001)$ and GF alone $(\mathrm{p}=0.001)$. GF alone, on the other hand, resulted in decreased BDNF expression, compared to that of norepinephrine ( $\mathrm{p}<$ $0.001)$, but significantly higher than that of vehicle controls $(\mathrm{p}<0.001)$. Veh, vehicle control; NE, norepinephrine $(100 \mathrm{nM})$; GF, bisindoylmaleimide $(5 \mu \mathrm{M}) ;{ }^{\star}$ Significantly different from vehicle controls. \#Significantly different from GF at $\mathrm{p}<0.001$.

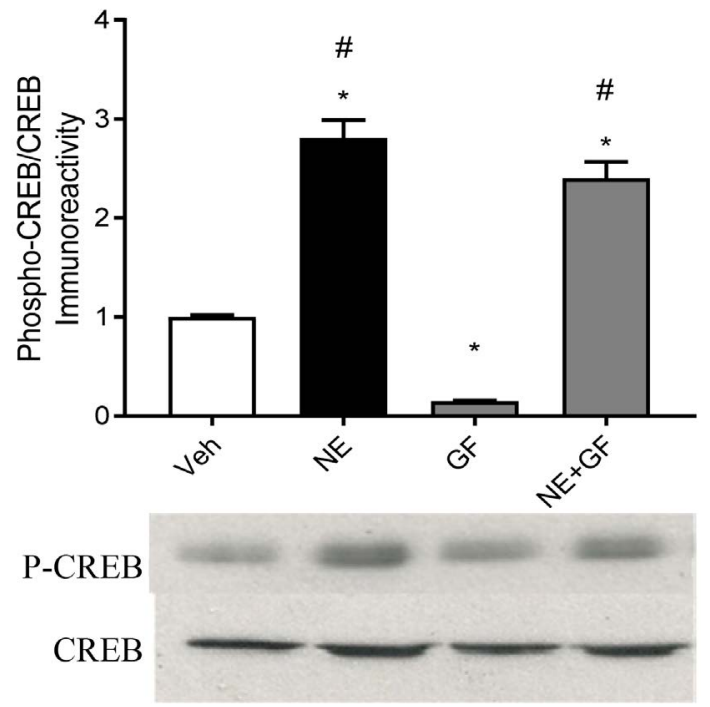

Figure 5. Norepinephrine increases, while GF decreases CREB phosphorylation. Norepinephrine alone $(\mathrm{p}<0.001)$ or when combined with GF $(\mathrm{p}=0.026)$ significantly increased phosphorylation of CREB above that of vehicle controls. GF, on the other hand, resulted in decreased CREB phosphorylation, compared to that of vehicle controls $(p<0.001)$. Norepinephrine significantly reversed the suppressing effects of GF, being significantly higher than that of GF alone ( $\mathrm{p}<0.001)$. Veh, vehicle control; NE, norepinephrine (100 $\mathrm{nM})$; GF, bisindoylmaleimide $(5 \mu \mathrm{M})$; ${ }^{\star}$ Significantly different from vehicle controls. \#Significantly different from GF at $\mathrm{p}<0.001$. 
implicates PKD as also responsible for phosphorylating CREB [61]. Other pathways/enzymes, such as CaMKII, which we did not evaluate, can still phosphorylate the transcription factor. Just as prior use of the PKA inhibitor, Rp-cAMPs, verified PKA involvement [55], our current use of the specific PKC/PKD inhibitor, bisindoylmaleimide, implicates $\mathrm{PKC/PKD} \mathrm{in} \mathrm{the} \mathrm{current} \mathrm{study.} \mathrm{Moreover,}$ our results of increased phosphorylation of GAP-43 as a result of norepinephrine as a stimulator indicate that neurite outgrowth may be partially G-protein-coupled receptor (GPCR)-dependent (Figure 3); likewise, GF inhibition of both GAP-43 (Figure 3) and $\mathrm{PKC} \delta_{\mathrm{S} 643}$ (Figure 1) phosphorylation lends support to the hypothesis that $\mathrm{PKC} \delta_{\mathrm{S} 643}$ is a mediator of neurite outgrowth. At the same time, norepinephrine stimulated GPCR-mediated increase in PKD activity, whether GF is present or not. Ultimately, norepinephrine via $\mathrm{PKC} \delta_{\mathrm{S} 643} / \mathrm{PKD} / \mathrm{PKC} \theta_{\mathrm{T} 538}$ led to increases in CREB activation and BDNF expression. Although CREB is a molecular [62] [63] [64] [65] [66] and behavioral [67] substrate for so many converging and cross-talking pathways, our findings that GF alone suppressed CREB phosphorylation (Figure 5) to a much greater statistical extent than it did in suppressing BDNF expression (Figure 4) could seem to defy explanation. However, it is possible that other protein kinase $\mathrm{c}$ isoforms that we did not evaluate (e.g., $\mathrm{PKC} \varepsilon$ ) were also sensitive to GF and consequently participated in suppressing CREB phosphorylation.

Herein, GF had no inhibitory effect on most of the other PKC isozymes, except for phospho-PKC $\delta_{5643}$. Developmentally, this isozyme reaches its peak expression at $2-3$ days in culture [13], which corresponds to the incubation period used in the current study. PKC $\alpha$ and $\mathrm{PKC} \beta$ show maximal expression only after 10 days in culture, while $\mathrm{PKC} \varepsilon$ (which was not evaluated in the current study) and $\mathrm{PKC} \lambda \zeta$ are maximal after only $1.5-2$ days in culture [13]. Therefore, one possible limitation of the current study would be that the effects of norepinephrine and/or GF were not evaluated when some of the isoforms (e.g., $\mathrm{PKC} \alpha, \beta, \varepsilon$, $\lambda \zeta, \mu)$ were at its peak expression in culture. This is the post plausible explanation for the negative findings regarding some of these isoforms. Another possible limitation of the study is that antidepressant drugs were not evaluated for any effects on the various PKC isoforms. Neurotransmitter-specific antidepressants, such as serotonin- or norepinephrine-selective re-uptake inhibitors, as previously done [8], would make this study more clinically applicable. Because PKC inhibition by GF has been shown to interfere with BDNF action [68] and excitatory neurotransmission [69], future studies should strive to determine which of the many PKC isozymes are most heavily involved in psychiatric, neurodevelopmental and neurodegenerative disorders.

\section{Acknowledgements}

Funded by PHS Grant MH 59776.

\section{References}

[1] Grillo, G., Montoya, A., Bruins, R., Katzman, M.A. and Blier, P. (2016) The Nora- 
drenergic Paradox: Implications in the Management of Depression and Anxiety. Neuropsychiatric Disease and Treatment, 12, 541-557. https://doi.org/10.2147/NDT.S91311

[2] Maletic, V., Eramo, A., Gwin, K., Offord, S.J. and Duffy, R.A. (2017) The Role of Norepinephrine and Its $\alpha$-Adrenergic Receptors in the Pathophysiology and Treatment of Major Depressive Disorder and Schizophrenia: A Systematic Review. Frontiers in Psychiatry, 8, 1-12. https://doi.org/10.3389/fpsyt.2017.00042

[3] Moriguchi, S., Yamada, M., Takano, H., Nagashima, T., Takahata, K., et al. (2017) Norepinephrine Transporter in Major Depressive Disorder: A PET Study. American Journal of Psychiatry, 174, 36-41. https://doi.org/10.1176/appi.ajp.2016.15101334

[4] Peacock, B.N., Scheiderer, D.J. and Kellermann, G.H. (2017) Biomolecular Aspects of Depression: A Retrospective Analysis. Comprehensive Psychiatry, 73, 168-180. https://doi.org/10.1016/j.comppsych.2016.11.002

[5] Russo-Neustadt, A.A. and Chen, M.J. (2005) Brain-Derived Neurotrophic Factor and Antidepressant Activity. Current Pharmaceutical Design, 11, 1495-1510. https://doi.org/10.2174/1381612053764788

[6] Chen, M.J. and Russo-Neustadt, A.A. (2007) Running Exercise- and Antidepressant-Induced Increases in Growth and Survival-Associated Signaling Molecules Are IGF-Dependent. Growth Factors, 25, 118-131. https://doi.org/10.1080/08977190701602329

[7] Chen, M.J. and Russo-Neustadt, A.A. (2009) Running Exercise-Induced Up-Regulation of Hippocampal Brain-Derived Neurotrophic Factor Is CREB-Dependent. Hippocampus, 19, 962-972. https://doi.org/10.1002/hipo.20579

[8] Chen, M.J., Nguyen, T.V., Pike, C.J. and Russo-Neustadt, A.A. (2007) Norepinephrine Induces BDNF and Activates the PI-3K and MAPK Cascades in Embryonic Hippocampal Neurons. Cellular Signaling, 19, 114-128. https://doi.org/10.1016/j.cellsig.2006.05.028

[9] Oehrlein, S.A., Maelicke, A. and Herget, T. (1998) Expression of Protein Kinase C Gene Family Members Is Temporally and Spatially Regulated during Neural Development In Vitro. European Journal of Cell Biology, 77, 323-337. https://doi.org/10.1016/S0171-9335(98)80091-5

[10] Purkayastha, S., Fernando, S.S., Diallo, S., Cohen, L., Ranasinghe, B., et al. (2009) Regulation of Protein Kinase C Isozymes during Early Post-Natal Hippocampal Development. Brain Research, 1288, 29-41. https://doi.org/10.1016/j.brainres.2009.06.074

[11] Huang, F.L., Yoshida, Y., Nakabayashi, H. and Huang, K.-P. (1987) Differential Distribution of Protein Kinase C Isozymes in the Various Regions of Brain. Journal of Biological Chemistry, 262, 15714-15720.

[12] Roisin, M.P. and Barbin, G. (1997) Differential Expression of PKC Isoforms in Hippocampal Neuronal Cultures: Modifications after Basic FGF Treatment. Neurochemistry International, 30, 261-270. https://doi.org/10.1016/S0197-0186(96)00095-2

[13] Tejero-Diez, P., Rodrigues-Sanchez, P. and Diez-Guerra, F.J. (1995) Expression of Protein Kinase C Isozymes in Hippocampal Neurones in Culture. FEBS Letters, 363, 293-298. https://doi.org/10.1016/0014-5793(95)00303-Q

[14] Newton, A.C. (1997) Regulation of Protein Kinase C. Current Opinion in Cell Biology, 9, 161-167. https://doi.org/10.1016/S0955-0674(97)80058-0

[15] Czöndör, K., Ellwanger, K., Fuchs, Y.F., Lutz, S., Gulyás, M., et al. (2009) Protein 
Kinase D Controls the Integrity of Golgi apparatus and the Maintenance of Dendritic Arborization in Hippocampal Neurons. Molecular Biology of the Cell, 20, 2108-2120. https://doi.org/10.1091/mbc.E08-09-0957

[16] Yin, D.-M., Huang, Y.-H., Zhu, Y.-B. and Wang, Y. (2008) Both the Establishment and Maintenance of Neuronal Polarity Require the Activity of Protein Kinase D in the Golgi apparatus. The Journal of Neuroscience, 28, 8832-8843. https://doi.org/10.1523/JNEUROSCI.1291-08.2008

[17] Bisbal, M., Conde, C., Donoso, M., Bollati, F., Sesma, J., et al. (2008) Protein Kinase D Regulates Trafficking of Dendritic Membrane Proteins in Developing Neurons. The Journal of Neuroscience, 28, 9297-9308. https://doi.org/10.1523/JNEUROSCI.1879-08.2008

[18] Avriyanti, E., Atik, N., Kunii, A., Furumoto, N., Iwano, T., et al. (2015) Functional Redundancy of Protein Kinase D1 and Protein Kinase D2 in Neuronal Polarity. Neuroscience Research, 95, 12-20. https://doi.org/10.1016/j.neures.2015.01.007

[19] Bencsik, N., Szíber, Z., Liliam, H., Tárnak, K., Borbély, S., et al. (2015) Protein Kinase D Promotes Plasticity-Induced F-Actin Stabilization in Dendritic Spines and Regulates Memory Formation. Journal of Cell Biology, 210, 771-783. https://doi.org/10.1083/jcb.201501114

[20] Routtenberg, A. (1985) Protein Kinase C Activation Leading to Protein F1 Phosphorylation May Regulate Synaptic Plasticity by Presynaptic Terminal Growth. Behavioral Neural Biology, 44, 186-200. https://doi.org/10.1016/S0163-1047(85)90184-0

[21] Lovinger, D.M. and Routtenberg, A. (1987) Protein F1 and Protein Kinase C May Regulate the Persistence, Not the Initiation, of Synaptic Potentiation in the Hippocampus. Advances in Experimental and Medical Biology, 221, 313-330. https://doi.org/10.1007/978-1-4684-7618-7_22

[22] Pasinelli, P., Ranmakers, G.M., Urban, I.J., Hens, J.J., Oestreicher, A.B., et al. (1995) Long-Term Potentiation and Synaptic Protein Phosphorylation. Behavioral Brain Research, 66, 53-59. https://doi.org/10.1016/0166-4328(94)00124-X

[23] Van der Zee, E.A., Luiten, P.G.M. and Disterhoft, J.F. (1997) Learning-Induced Alterations in Hippocampal PKC-Immunoreactivity: A Review and Hypothesis of Its Functional Significance. Progress in Neuropsychopharmacology and Biological Psychiatry, 21, 531-572. https://doi.org/10.1016/S0278-5846(97)00017-1

[24] Fagnou, D.D. and Tuchek, J.M. (1995) The Biochemistry of Learning and Memory. Molecular and Cell Biochemistry, 149-150, 279-286. https://doi.org/10.1007/BF01076589

[25] Riedel, G. (1997) Protein Kinase C: A Memory Kinase? Progress in Neuropsychopharmacology and Biological Psychiatry, 21, 373-378. https://doi.org/10.1016/S0278-5846(97)00009-2

[26] Choi, M., Lee, S.H., Wang, S.E., Ko, S.Y., Song, M., et al. (2015) Ketamine Produces Antidepressant-Like Effects through Phosphorylation-Dependent Nuclear Export of Histone Deacetylase 5 (HDAC5) in Rats. Proceedings of the National Academy of Sciences, USA, 112, 15755-15760. https://doi.org/10.1073/pnas.1513913112

[27] Krueger, D.D., Osterwell, E.K. and Bear, M.F. (2010) Activation of mGluR5 Induces Rapid and Long-Lasting Protein Kinase D Phosphorylation in Hippocampal Neurons. Journal of Molecular Neuroscience, 42, 1-8. https://doi.org/10.1007/s12031-010-9338-9

[28] Wang, H., Ardiles, A.O., Yang, S., Tran, T., Posada-Duque, R., et al. (2016) Metabotropic Glutamate Receptors Induce a Form of LTP Controlled by Translation and 
Arc Signaling in the Hippocampus. The Journal of Neuroscience, 36, 1723-1729. https://doi.org/10.1523/JNEUROSCI.0878-15.2016

[29] Schwab, M.E. (1996) Structural Plasticity of the Adult CNS. Negative Control by Neurite Growth Inhibitory Signals. International Journal of Developmental Neuroscience, 14, 379-385. https://doi.org/10.1016/0736-5748(96)00024-X

[30] Melberg, P.J. and Routtenberg, A. (1991) Selective Expression of Protein F1/(GAP-43) mRNA in Pyramidal But Not Granule Cells of the Hippocampus. Neuroscience, 45, 721-733. https://doi.org/10.1016/0306-4522(91)90284-U

[31] Oehrlein, S.A., Parker, P.J. and Herget, T. (1996) Phosphorylation of GAP-43 (Growth-Associated Protein of $43 \mathrm{kDa}$ ) By Conventional, Novel and Atypical Isotypes of the Protein Kinase C Gene Family: Differences between Oligopeptide and Polypeptide Phosphorylation. Biochemical Journal, 317, 219-224.

https://doi.org/10.1042/bj3170219

[32] Leal, G., Comprido, D. and Duarte, C.B. (2014) BDNF-Induced Local Protein Synthesis and Synaptic Plasticity. Neuropharmacology, 76, 639-656. https://doi.org/10.1016/j.neuropharm.2013.04.005

[33] Molteni, R., Barnard, R.J., Ying, Z., Roberts, C.K. and Gomez-Pinilla, F. (2002) A High-Fat, Refined Sugar Diet Reduces Hippocampal Brain-Derived Neurotrophic Factor, Neuronal Plasticity, and Learning. Neuroscience, 112, 803-814. https://doi.org/10.1016/S0306-4522(02)00123-9

[34] Murinová, J., Hlavácová, N., Chmelová, M. and Riecansky, I. (2017) The Evidence for Altered BDNF Expression in the Brain of Rats Reared or Housed in Social Isolation: A Systematic Review. Frontiers in Behavioral Neuroscience, 11, 101. https://doi.org/10.3389/fnbeh.2017.00101

[35] Ranmakers, G.M., Pasinelli, P., Hens, J.J., Gispen, W.H. and De Graan, P.N. (1997) Protein Kinase C in Synaptic Plasticity: Changes in the In Situ Phosphorylation State of Identified Pre- and Postsynaptic Substrates. Progress in Neuropsychopharmacology Biological Psychiatry, 21, 455-486. https://doi.org/10.1016/S0278-5846(97)00013-4

[36] Chao, H.M., Sakai, R.R., Ma, L.Y. and McEwen, B.S. (1998) Adrenal Steroid Regulation of Neurotrophic Factor Expression in the Rat Hippocampus. Endocrinology, 139, 3112-3118. https://doi.org/10.1210/endo.139.7.6114

[37] Larsen, M.H., Hay-Schmidt, A., Rфnn, L.C. and Mikkelsen, J.D. (2008) Temporal Expression of Brain-Derived Neurotrophic Factor (BDNF) mRNA in the Rat Hippocampus after Treatment with Selective and Mixed Monoaminergic Antidepressants. European Journal of Pharmacology, 578, 114-122. https://doi.org/10.1016/j.ejphar.2007.08.050

[38] Ding, Q., Ying, Z. and Gomez-Pinilla, F. (2011) Exercise Influences Hippocampal Plasticity by Modulating Brain-Derived Neurotrophic Factor Processing. Neuroscience, 192, 773-780. https://doi.org/10.1016/j.neuroscience.2011.06.032

[39] Liu, J., He, Q.J., Zou, W., Wang, H.X., Bao, Y.M., et al. (2006) Catalpol Increases Hippocampal Neuroplasticity and Up-Regulates PKC and BDNF in the Aged Rats. Brain Research, 1123, 68-79. https://doi.org/10.1016/j.brainres.2006.09.058

[40] Vilberg, H., Mundy, W. and Eriksson, P. (2008) Neonatal Exposure to Decabrominated Diphenyl Ether (PBDE 209) Results in Changes in BDNF, CaMKII and GAP-43, Biochemical Substrates of Neuronal Survival, Growth, and Synaptogenesis. Neurotoxicology, 29, 152-159. https://doi.org/10.1016/j.neuro.2007.10.007

[41] Miyake, K., Yamamoto, W., Tadokoro, M., Takagi, N., Sasakawa, K., et al. (2002) Alterations in Hippocampal GAP-43, BDNF, and L1 Following Sustained Cerebral 
Ischemia. Brain Research, 935, 24-31. https://doi.org/10.1016/S0006-8993(02)02420-4

[42] Prosser-Loose E.J., Verge, V.M., Cayabyab, F.S. and Paterson, P.G. (2010) Protein-Energy Malnutrition Alters Hippocampal Plasticity-Associated Protein Expression Following Global Ischemia in the Gerbil. Current Neurovascular Research, 7, 341-360. https://doi.org/10.2174/156720210793180792

[43] Gordon, T. (2009) The Role of Neurotrophic Factors in Nerve Regeneration. Neurosurgery Focus, 26, E3. https://doi.org/10.3171/FOC.2009.26.2.E3

[44] Rosenbrock, H., Koros, E., Bloching, A., Podhorna, J. and Borsini, F. (2005) Effect of Chronic Intermittent Restraint Stress on Hippocampal Expression of Marker Proteins for Synaptic Plasticity and Progenitor Cell Proliferation in Rats. Brain Research, 1040, 55-63. https://doi.org/10.1016/j.brainres.2005.01.065

[45] Kuroda, Y. and McEwen, B.S. (1998) Effect of Chronic Restraint Stress and Tianeptine on Growth Factors, Growth-Associated Protein-43 and Microtubule-Associated Protein 2 mRNA Expression in the Rat Hippocampus. Brain Research Molecular Brain Research, 59, 35-39. https://doi.org/10.1016/S0169-328X(98)00130-2

[46] Tandon, P., Yang, Y., Das, K., Holmes, G.L. and Stafstrom, C.E. (1999) Neuroprotective Effects of Brain-Derived Neurotrophic Factor in Seizures during Development. Neuroscience, 91, 293-303. https://doi.org/10.1016/S0306-4522(98)00609-5

[47] Ma, J., Zhang, Z., Su, Y., Kang, L., Geng, D., et al. (2013) Magnetic Stimulation Modulates Structural Synaptic Plasticity and Regulates BDNF-TrkB Signal Pathway in Cultured Hippocampal Neurons. Neurochemistry International, 62, 84-91. https://doi.org/10.1016/j.neuint.2012.11.010

[48] Zafra, F., Lindholm, D., Castrén, E., Hartikka, J. and Thoenen, H. (1992) Regulation of Brain-Derived Neurotrophic Factor and Nerve Growth Factor mRNA in Primary Cultures of Hippocampal Neurons and Astrocytes. The Journal of Neuroscience, 12, 4793-4799.

[49] Chen, M.J. and Russo-Neustadt, A.A. (2013) Kinetics of Norepinephrine- and Serotonin-Induced BDNF Release in Cultured Embryonic Hippocampal Neurons. Neuroscience \& Medicine, 4, 194-207. https://doi.org/10.4236/nm.2013.44031

[50] Banker, G.A. and Cowan, W.M. (1977) Rat Hippocampal Neurons in Dispersed Cell Culture. Brain Research, 126, 397-442. https://doi.org/10.1016/0006-8993(77)90594-7

[51] Gekeler, V., Boer, R., Uberall, F., Ise, W., Schubert, C., et al. (1996) Effects of the Selective Bisindoylmaleimide Protein Kinase C Inhibitor GF109203X on P-Glycoprotein-Mediated Multidrug Resistance. British Journal of Cancer, 74, 897-905. https://doi.org/10.1038/bjc.1996.454

[52] Laemmli, U.K. (1970) Cleavage of Structural Proteins during the Assembly of the Head of Bacteriophage T4. Nature, 227, 680-685. https://doi.org/10.1038/227680a0

[53] Lowry, O.H., Rosebrough, N.J., Farr, A.L. and Randall, R.J. (1951) Protein Measurement with the Folin Phenol Reagent. Journal of Biological Chemistry, 193, 265-275.

[54] Patel, N.J., Chen, M.J. and Russo-Neustadt, A.A. (2010) Norepinephrine and Nitric Oxide Promote Cell Survival Signaling in Hippocampal Neurons. European Journal of Pharmacology, 633, 1-9. https://doi.org/10.1016/j.ejphar.2010.01.012

[55] Yang, D., Chen, M. and Russo-Neustadt, A. (2012) Antidepressants Are Neuroprotective against Nutrient Deprivation Stress in Hippocampal Neurons. European Journal of Neuroscience, 36, 2573-2587. 
https://doi.org/10.1111/j.1460-9568.2012.08187.x

[56] Dwivedi, Y. and Pandey, G.N. (2008) Adenylyl Cyclase-cyclicAMP Signaling in Mood Disorders: Role of the Crucial Phosphorylating Enzyme Protein kInase A. Neuropsychiatric Disease and Treatment, 4, 161-176. https://doi.org/10.2147/NDT.S2380

[57] Carreno, F.R. and Fraer, A. (2014) Activation of Signaling Pathways Downstream of the Brain-Derived Neurotrophic Factor Receptor, TrkB, in the Rat Brain by Vagal Nerve Stimulation and Antidepressant Drugs. International Journal of Neuropsychopharmacology, 17, 247-258. https://doi.org/10.1017/S1461145713000977

[58] Xia, Z. and Storm, D.R. (2012) Role of Signal Transduction Crosstalk between Adenylyl Cyclase and MAP Kinase in Hippocampus-Dependent Memory. Learning and Memory, 19, 369-374. https://doi.org/10.1101/lm.027128.112

[59] Peltier, J., O’Neill, A. and Schaffer, D.V. (2007) PI3K/Akt and CREB Regulate Adult Neural Hippocampal Progenitor Proliferation and Differentiation. Developmental Neurobiology, 67, 1348-1361. https://doi.org/10.1002/dneu.20506

[60] Racaniello, M., Cardinale, A., Mollinari, C., D’Antuono, M., De Chiara, G., et al. (2010) Phosphorylation Changes of CaMKII, ERK1/2, PKB/Akt Kinases and CREB Activation during Early Long-Term Potentiation at Schaffer colLateral-CA1 Mouse Hippocampal Synapses. Neurochemical Research, 35, 239-246.

https://doi.org/10.1007/s11064-009-0047-0

[61] Johannessen, M., Delghandi, M.P., Rykx, A., Dragset, M., Vandenheede, J.R., et al. (2007) Protein Kinase D Induces Transcription through Direct Phosphorylation of the cAMP-Response Element-Binding Protein. Journal of Biological Chemistry, 282, 14777-14787. https://doi.org/10.1074/jbc.M610669200

[62] Benito, E. and Barco, A. (2010) CREB's Control of Intrinsic and Synaptic Plasticity: Implications for CREB-Dependent Memory Models. Trends in Neuroscience, 33, 230-240. https://doi.org/10.1016/j.tins.2010.02.001

[63] Lee, D. (2015) Global and Local Missions of cAMP Signaling in Neural Plasticity, Learning, and Memory. Frontiers in Pharmacology, 6, 1-7. https://doi.org/10.3389/fphar.2015.00161

[64] Nair, A. and Vaidya, V.A. (2006) Cyclic AMP Response Element Binding Protein and Brain-Derived Neurotrophic Factor: Molecules That Modulate Our Mood? Journal of Bioscience, 31, 423-424. https://doi.org/10.1007/BF02704114

[65] Sakamoto, K., Karelina, K. and Obrietan, K. (2011) CREB: A Multifaceted Regulator of Neuronal Plasticity and Protection. Journal of Neurochemistry, 116, 1-9. https://doi.org/10.1111/j.1471-4159.2010.07080.x

[66] Tardito, D., Perez, J., Tiraboschi, E., Musazzi, L., Racagni, G., et al. (2006) Signaling Pathways Regulating Gene Expression, Neuroplasticity, and Neurotrophic Mechanisms in the Action of Antidepressants: A Critical Overview. Pharmacological Reviews, 58, 115-134. https://doi.org/10.1124/pr.58.1.7

[67] Marsden, W.N. (2013) Synaptic Plasticity in Depression: Molecular, Cellular and Functional Correlates. Progress in Neuropsychopharmacology and Biological Psychiatry, 43, 168-184. https://doi.org/10.1016/j.pnpbp.2012.12.012

[68] Ortiz-Lopez, L., Vega-Rivera, N.M., Babu, H. and Ramirez-Rodriguez, G.B. (2017) Brain-Derived Neurotrophic Factor Induces Cell Survival and the Migration of $\mathrm{Mu}$ rine Adult Hippocampal Precursor Cells during Differentiation In Vitro. Neurotoxicology Research, 31, 122-135. https://doi.org/10.1007/s12640-016-9673-x

[69] Capogna, M., Fankhauser, C., Gagliardini, V., Gähwiler, B.H. and Thompson, S.M. 
(1999) Excitatory Synaptic Transmission and Its Modulation by PKC Is Unchanged in the Hippocampus of GAP-43-Deficient Mice. European Journal of Neuroscience, 11, 433-440. https://doi.org/10.1046/j.1460-9568.1999.00450.x 